University of South Florida

DIGITAL COMMONS

Digital Commons @ University of

@ UNIVERSITY OF SOUTH FLORIDA

South Florida

QMaSC: A Handbook for Directors of

Quantitative and Mathematics Support Centers

USF Libraries

$1-1-2016$

\title{
29. Case Study: The Math Study Center at the University of Washington
}

Patrick T. Perkins

University of Washington

Follow this and additional works at: https://digitalcommons.usf.edu/qmasc_handbook

\section{Recommended Citation}

Patrick T. Perkins (2016), "Case Study: The Math Study Center at the University of Washington", http://dx.doi.org/10.5038/9780977674435.ch29 in G. Coulombe, M. O'Neill, M. Schuckers (Eds.) A Handbook for Directors of Quantitative and Mathematical Support Centers, Neck Quill Press, http://scholarcommons.usf.edu/qmasc_handbook.

This Case Studies is brought to you for free and open access by the USF Libraries at Digital Commons @ University of South Florida. It has been accepted for inclusion in QMaSC: A Handbook for Directors of Quantitative and Mathematics Support Centers by an authorized administrator of Digital Commons @ University of South Florida. For more information, please contact digitalcommons@usf.edu. 


\section{Case Study: The Math Study Center at the University of Washington}

(c) Patrick T. Perkins,

University of Washington

प्र

\section{Introduction and History}

The Math Study Center, a large tutoring facility at the University of Washington in Seattle, is run and funded by the Department of Mathematics. Its mission is to serve students taking large freshman mathematics classes at the UW. The Center serves students of precalculus as well as the three quarters of freshman calculus. The MSC was started in 1992 by Ken Plochinski, who had previously run a similar facility at the University of Michigan that was the source of the main ideas behind the MSC. The author took over as Director from 2000 to 2013, inheriting a smoothly run organization requiring very few changes. The Math Study Center, while being a great place for students to work on math regardless of whether or not they need help, is not a tutoring center in the traditional sense. It provides a comfortable place and a supportive atmosphere for students to come together and study, in groups or individually. The MSC is staffed by a number of tutors, both graduate student TAs and advanced undergraduates. The mathematics graduate students work at the center as part of their TA job and professors hold their office hours in the MSC. Tutors sit with students to help them get unstuck or to answer questions. The center does not provide long blocks of uninterrupted one-on-one tutoring. Textbooks, calculators, and other study materials may to

Suggested Citation: Patrick T. Perkins (2016), "Case Study: The Math Study Center at the University of Washington", http://dx.doi.org/10.5038/9780977674435.ch29 in G. Coulombe, M. O'Neill, M. Schuckers (Eds.) A Handbook for Directors of Quantitative and Mathematical Support Centers, Neck Quill Press, http: //scholarcommons.usf.edu/qmasc_handbook

This material is based upon work supported, in part, by the National Science Foundation under Grant DUE1255945. Any opinions, findings, and conclusions or recommendations expressed in this material are those of the author(s) and do not necessarily reflect the views of the National Science Foundation 
be checked out for in-room use. A unique feature of the MSC is the variety of kinds of help the students can receive.

The MSC occupies a large room in the basement of the Communications Building, across the street from the Department of Mathematics. It is open Monday through Thursday from 9:30am to 9:30pm. It is also open Friday from 9:30am to 1:30pm and Sunday from 2:00pm to 6:00pm. When students enter the MSC, a desk assistant greets them at the front desk. The director's office and a small conference room are to the right. The main room, left of the entrance, is a square about 40 feet on each side. A variety of math related posters cover the walls. Many colorful cardboard polyhedrons, made by a math class years ago, hang from the ceiling. The room contains 8 large tables, each seating 10 students. Five smaller tables are scattered around the room. The large tables are arranged in 4 groups, two tables for each of the four classes that are served by the MSC. There are signs over the tables indicating which classes they are for. Ideally, students in the same class should sit together and help each other or perhaps form study groups. Seven cubicles with tables, chairs, and whiteboards are located around the outside of the room near the walls. The cubicles can be used by students who form study groups. They are also used by professors and teaching assistants to hold their office hours.

\section{Center Management and Services}

The author of this case study, who served as director of the Math Study Center for 13 years, is a Senior Lecturer in Mathematics at the University of Washington. The director taught four classes per year because the duties of Director count for half of the usual teaching load of eight classes. During that time, the director's office was in the MSC, across the street from the rest of the math department. Students frequently dropped in to ask questions. The director's duties included hiring, handling payroll, staffing, and scheduling. Scheduling, which is a significant task in a facility the size of the MSC, will be discussed later.

When the author started, he had no managerial experience beyond dealing with the TAs and graders for his classes. Learning to be a good manager was a significant part of the job. Dealing with more than 20 employees in their twenties often involved small weekly dramas. As such, the director had to be flexible and responsive to illnesses, as well as exam and homework jitters. One tutor had a sex change which among other things required the director to deal with the medical issues, as well as less evolved attitudes on the part of some of the other workers. It was important to build a sense of being a team among the workers. That way if one has a crisis, another is willing to cover for them. The director spoke to each of the workers at least once every two weeks. Often it was just a short conversation, involving details about previous chats such as how they did on a big midterm or how their first research talk went. This method fostered some trust and goodwill setting the groundwork for eventual talks with them about repeated lateness or poor tutoring. 
The Math Department has a Chair, a position that rotates every few years, and a Department Administrator, a staff position. The MSC director reports to both of these people. At the beginning of each quarter, the director computes and submits an estimated budget to the Administrator for approval since the MSC is funded by the Math Department budget. While the Chair was always included in this email, the director deals mainly with this Administrator. Occasionally, the Chair stops by the MSC to see how things are going, but most of the time the director is left to run things as he sees fit. The director meets annually with the Chair and to give an update on the MSC. Because the graduate students who work as tutors are assigned to the MSC by the head of the Student Services office in the Math Department, the director works closely with her on staffing matters.

Originally, the director spent the various breaks creating work schedules for the next quarter, juggling about 25 student workers, each of whom was only available certain hours each day. Historical information about when the MSC was busy enabled the director to estimate how many tutors might be needed each hour. The director would spend about a week moving names into little boxes, trying to come up with a feasible schedule. Then he would meet with all of the workers on the first day of the quarter so that they could trade hours with each other until things were reasonably satisfactory. Tired of spending breaks in this way, the director wrote some heuristic software that proved fairly helpful. Things really improved when the Math Department hired Rekha Thomas, an expert in discrete optimization. She assigned, to a team of undergraduate optimization students, the project of solving the MSC scheduling problem. This team, led by Caleb White, came up with a very sophisticated solution to the problem, which did much more than just give a feasible solution used as a base for trading. The team implemented some very sophisticated constraints. For example, tutors do not like to enter and leave the MSC more than twice a day. Or, if they have a free hour between two classes, they often like to work at that time. The numerous features of the project are provided in a published paper [1]. Given that the system was written by mathematicians for mathematicians, it is not terribly user friendly and could use some work in this area. But it does an excellent job of making good schedules and takes about 6 seconds to run, rather than a week by hand.

\section{$3 \quad$ Staffing, Hiring and Training}

In Autumn 2012, a typical quarter, the MSC employed 15 undergraduate tutors and 6 math graduate students assigned to the MSC as part of their TA duties. The undergraduates worked between 8 and 12 hours a week. The grad students worked 6 or 12 hours a week, depending on their assignment. There were up to 100 students using the MSC at peak times during that quarter. The average number was about 50. We do not want students waiting 45 minutes for a tutor. Therefore, tutors are required to limit the time spent with each student to no more than 10 minutes. The 
ideal session is for the tutor to quickly get the student unstuck and back to work. Students are encouraged to talk to each other and get help in this way. There is a sign-up sheet on the wall that the students use to get help from a tutor. If the number of people on the list gets large, the director helps with the tutoring.

The bulk of the hiring for the year is completed during August. The undergraduate tutors are mostly students recruited from classes recently taught by the director. When serving as Director, the author often interviewed 25 people and hired about 5 each year. In interviews, he sought to get an impression of the candidate's character in addition to looking for people with good social skills, as well as the required math ability. The director also gave candidates a test on basic calculus. This open-book, untimed test was a list of problems from the calculus text used at the UW. The author admits that his hiring procedures could use some improvement, but they served him well enough for many years. No training was offered to the new tutors. Instead, the large number of returning tutors each year served as mentors to the new people. The director kept an eye on the new tutors during the first few weeks of their first quarter and answered many questions. It could be a little rough at first, but after a couple of weeks they always settled in and became comfortable with the job.

Each year the director also hired 4 or 5 friendly, helpful students to work as desk assistants. The desk assistant is the first person that a new student greets upon arrival. Because the director is not able to be in the MSC for all of the open hours, the desk assistants serve to keep an eye on the Center. They answer many student questions, particularly during the Autumn quarter. Desk assistants also check the tutors in and out on a time sheet and inform the director if a tutor is regularly late. There are books and calculators available for use in the MSC and the desk assistants took care of checking these in and out.

\section{Community Interactions}

At the first math faculty meeting of the school year, the director makes an announcement to describe the MSC, give the open hours, and encourage the instructors to refer their students. An email announcement is sent to the Math Department at the beginning of each quarter. Calculus instructors are given an overhead slide with information about the MSC. But most students already know about the MSC services and have no trouble finding their way to the Center. Word of mouth is the most effective advertisement.

The director maintains contact with the several other facilities on UW campus that offer math tutoring. Because the MSC usually has more job applicants each year than can be hired, the directors provides useful references to the other centers regarding those candidates that were interviewed and tested but not hired by the MSC. 
On a number of occasions, people from outside the UW work as volunteer tutors in the MSC. These people are mostly recent immigrants who have not yet received a work permit. They seek to gain work experience and practice speaking English. Often, the director writes them a job letter later on.

The MSC occasionally receives phone calls from people in the Seattle area seeking help with various math-related issues such as fielding inquiries from parents seeking tutors for their children. The Math Department maintains a list of tutors for hire and the director is familiar with many of the people on the list. The director makes suggestions and asks for feedback on how things go. Sometimes people call with general math questions. When unable to give a good answer, the director gets them in touch with someone who is more knowledgeable on the topic.

\section{Assessment at the Center}

The director maintains an anonymous email account for student comments about the MSC. Despite getting many comments over the years, the author received very few complaints about the quality of tutoring provided. Several times a quarter the desk assistants take a census of the MSC. Every half an hour, for a week, they count the number of students using the center. This information is very useful when scheduling tutors for future quarters. As previously mentioned, when it gets busy in the MSC, the director helps with the tutoring. This helps to build the sense of being a team, and gave the director the chance to show the tutors how to serve students effectively in a short amount of time. Working directly with students enables the director to get informal feedback on how the MSC is doing. A few years ago, the Math Department ran a large program aimed at getting student feedback on the calculus sequence. The clear and strong message is that students valued the MSC highly and were very satisfied with the service they received.

\section{Additional Topics}

This year, academic year 2013-14, was my last running the Math Study Center. After 13 years I am returning to teaching full time and another faculty member is taking over. I look back with some satisfaction on the experience. I have learned that I am a pretty good boss. Hiring friendly, competent people and letting them get on with the job seems to be the secret. I had a very diverse group but wove them into a team by regularly interacting with them in a friendly way. I set clear goals and then let the workers figure out how best to fill them. I worked alongside them to set an example. Many workers came back year after year, in spite of the low wages forced on us by the state budget cuts. I also had fun with the scheduling problem. I learned a lot about discrete optimization and gained a new appreciation of how math can really be used. The MSC is 
a successful organization that provides a useful service at the UW. I can see some changes coming, mostly related to technology and computers. But this is for my successor to think about.

\section{Bibliography}

[1] C. Z. White, Y. Lee, Y. Kim, R. Thomas, and P. Perkins, "Creating weekly timetables for maximizing employee preferences," The UMAP Journal, vol. 25, no. 1, pp. 5-24, 2004. http: //www.math.washington.edu/ thomas/papers/MSCRevised.pdf. 